\title{
Influence of Gamma Irradiation and Water Aging on the Space Charge Characteristics of Epoxy Micro-Nano Composites
}

\author{
Myneni Sukesh Babu ${ }^{1}$, Ramanujam Sarathi ${ }^{1, *}$, Takahiro Imai ${ }^{2}$ and Toshikatsu Tanaka ${ }^{3}$ \\ 1 Department of Electrical Engineering, Indian Institute of Technology Madras, Chennai 600036, India; \\ ee18d003@smail.iitm.ac.in \\ 2 Infrastructure Systems Research and Development Center, Toshiba Infrastructure Systems \& Solutions \\ Corporation, Toshiba-cho, Fuchu-shi, Tokyo 183-8511, Japan; takahiro2.imai@toshiba.co.jp \\ 3 Electrical and Electronics Department, IPS Research Centre, Waseda University, Kitakyushu 808-0135, Japan; \\ t-tanaka@waseda.jp \\ * Correspondence: rsarathi@iitm.ac.in
}

Citation: Sukesh Babu, M.; Sarathi,

R.; Imai, T.; Tanaka, T. Influence of

Gamma Irradiation and Water Aging on the Space Charge Characteristics of Epoxy Micro-Nano Composites. Polymers 2021, 13, 964. https:// doi.org/10.3390/polym13060964

Academic Editor: Sombel Diaham

Received: 27 February 2021

Accepted: 15 March 2021

Published: 22 March 2021

Publisher's Note: MDPI stays neutral with regard to jurisdictional claims in published maps and institutional affiliations.

Copyright: (c) 2021 by the authors. Licensee MDPI, Basel, Switzerland. This article is an open access article distributed under the terms and conditions of the Creative Commons Attribution (CC BY) license (https:/ / creativecommons.org/licenses/by/ $4.0 /)$.

\begin{abstract}
Epoxy micro-nano composites are well-known to exhibit enhanced electrical, mechanical as well as thermal properties compared to base epoxy resin. Yet, a clear understanding need to be achieved on the long-term aging performance of the epoxy micro-nano composites. The present review article is a comprehensive study on the impact of gamma irradiation and water aging on the space charge characteristics of epoxy micro-nano composites that are applicable as insulant in highvoltage power apparatus. Ion-trapping nanoparticles, which possess good oxidation resistance and high ion trapping ability, are being chosen as nanofillers along with silica micro fillers in epoxy micronano composite material for improving the reliability of electrical insulation structures. The epoxy micro-nano composite specimens were subjected to gamma irradiation (4 kGy and $8 \mathrm{kGy}$ ) and water aging (under room temperature and at $90^{\circ} \mathrm{C}$ ), to analyze the effect of aging on space charge accumulation and charge decay characteristics. The mean magnitude of accumulated space charge density of epoxy micro-nano composites tends to increase with an increase in gamma irradiation dose as well as an increment in water diffusion coefficient. The mean lifetime of the space charge decay during depoling has significantly reduced after gamma irradiation and is converse with water aged specimen. Voltage polarity reversal studies have indicated that a part of homo-charge injected from electrodes remained as hetero-charge just after polarity reversal and could result in the distortion of electric field thereby increasing the electric field enhancement factor.
\end{abstract}

Keywords: epoxy; micro-nano composites; silica; ion-trapping nano particle; gamma irradiation; water aging; space charge

\section{Introduction}

In recent years, polymeric nanocomposite insulating materials such as epoxy nanocomposites are gaining attention to be used as an insulant in power apparatus like rotating machines, cast resin dry-type transformers, and as spacers in Gas Insulating Switchgear (GIS) [1-3]. Because of the high surface area of the fillers, it is possible to achieve improved properties such as higher volume resistivity, higher breakdown strength, lower space charge accumulation, and lower dielectric loss by reinforcing small quantities of micro or nano particles into the epoxy matrix [4-7]. The electrical, mechanical, and thermal properties of polymeric nanocomposites depend on the type of polymer matrix and filler, their physical properties such as size, shape, and weight percentage of the fillers [8-13]. Proper dispersion of the micro or nano particles in the polymer matrix also plays a crucial role in the improvement of desired properties of the composite material [14]. Hence, it is essential to determine the optimal weight percentage of filler in a polymer matrix. 
A considerable amount of work has been carried in the recent studies to understand the behavior of epoxy resin by adding micro or nano fillers such as clays (montmorillonite), inorganic oxides such as silica, alumina, titania, magnesia, zinc oxide, etc., and metal particles such as aluminum, nickel, and silver [15-24]. Imai et al. have stated that the silica micro particles exhibit low coefficient of thermal expansion [25]. In addition, Goyanes et al. have stated that the addition of the silica micro fillers tends to improve storage modulus along with inhibiting thermal expansion coefficient of the composites [26]. Tsekmes et al. have indicated that the epoxy micro-nano composites can have the advantages of higher breakdown strength and improved thermal conductivity [27]. The use of 60-70 wt.\% of micro-sized silica particles as filler in epoxy composite insulators is a general trend in industry [27]. Mishra et al. have studied about the corona discharges initiated due to water droplets on ion-trapping nano particle-filled epoxy nanocomposites. An ion-trapping nano particle is a hydrotalcite compound modified with zirconium phosphate. Inorganic ion exchangers like zirconium phosphate tend to exhibit good oxidation resistance along with high ion trapping ability. Hence, it can be applicable in the electrical insulation structures for improving their reliability [28]. Furthermore, it can enhance the thermal capability of the insulating material, because of the presence of zirconium, a refractory material [29]. Additionally, the study on the influence of reinforcing inorganic ion exchangers into epoxysilica micro composites, in order to use them as insulant, is discussed very little $[29,30]$, and a proper database needs to be established.

The exposure of polymeric insulating materials to various stresses during their usage may deteriorate its properties and may lead to its early degradation [31-35]. In radiation environments such as nuclear power plants and space equipment, the application of epoxy insulating materials is increasing rapidly $[28,36]$. Hence, it is necessary to analyze the performance of the epoxy nanocomposites with respect to different levels of gammaray irradiation. The ionizing radiations can alter the molecular structure of polymeric insulating materials through different physical and chemical mechanisms like cross-linking, chain scissions, and oxidation [37]. These structural changes induced due to the exposure of gamma radiation tends to alter the space charge and charge trap characteristics of insulating material [38]. One of the major concerns in epoxy nanocomposite insulating material is the tendency of water uptake in humid environments. Water diffused into the epoxy composite specimens is present in the free volume of the micro cavities in the matrix and can also present as bound water, which forms hydrogen-bonding with polar segments of the material [39]. This phenomenon is severe in case of composites compared to base epoxy matrix, as the matrix-filler interface acts as a potential site for the water molecules to interact [40]. It can also lead to irreversible material changes such as plasticization and swelling [41]. Epoxy specimens are subjected to water aging at high temperatures in order to simulate the accelerated ageing and to understand the long-term consequences of water intake phenomenon [42].

Polymeric insulating materials under high electric fields tend to accumulate charge in the volume of the specimen. This accumulated space charge can alter the internal electric field, resulting in the early degradation of insulating material [43-46]. Noah et al. have indicated that the DC electric fields above $3 \mathrm{kV} / \mathrm{mm}$ can trigger space charge accumulation in the epoxy resin [47]. The voltage polarity reversal phenomenon in general happens in HVDC transmission systems for achieving bi-directional power flow. The presence of space charge during the voltage polarity reversal can become a vital threat to the insulation cables in HVDC system $[48,49]$. Chen et al. have indicated that the dosage of gamma radiation as well as ambience of radiation can significantly affect the space charge accumulation in the insulating material [50]. Montanari et al. have stated that the presence of humidity can enhance space charge accumulation, which can possibly affect the charge trapping sites [51]. The water shell model proposed by Zou et al., which is based on Lewis' [52] and Tanaka's [53] models, explains the effect of water absorption in epoxy nanocomposites when they are exposed to humidity [40]. If the water concentration around the nanoparticles is high, percolative paths are formed through overlapping water shells 
that can affect the dielectric properties of epoxy nanocomposites [47]. So, it is essential to understand the influence of gamma radiation and water aging on the space charge accumulation under different electric fields and during polarity reversal. Various methods have been employed to measure the space charge in the insulating material including thermal step method (TSM), Laser Induced Pressure Pulse (LIPP), Pulse Electro Acoustic (PEA), Pressure Wave Propagation (PWP), etc., and each method has its own advantages and disadvantages. Of these, the Pulse Electro Acoustic (PEA) method is one of the most reliable and promising technique for the measurement of space charge [54]. Hence, in the present study, PEA method of space charge measurement has been employed.

Therefore, the prime focus of the present review paper is to assess the long-term aging performance and to establish a proper database on the influence of various aging conditions on the space charge accumulation and charge decay characteristics of epoxy micro-nano composites, under positive DC electric field and during voltage polarity reversal phenomenon.

\section{Experimental Setup and Aging Procedure}

\subsection{Specimen Details}

The epoxy micro-nano composite specimen, which consists of base epoxy resin reinforced with crystalline $\mathrm{SiO}_{2}$ micro fillers ( $66 \mathrm{wt} . \%$ ) ion-trapping nano particles as nano fillers $(0.7 \mathrm{wt} . \%)$. The $\mathrm{SiO}_{2}$ micro fillers and the ion-trapping nano fillers have an average diameter of $14 \mu \mathrm{m}$ and $200-500 \mathrm{~nm}$, respectively. Surface modification of fillers by silane coupling agent has been employed. Epoxy micro-nanocomposites specimens were prepared by following the standard shear mixing, degassing, casting, and curing procedures as shown in Figure 1 [29].

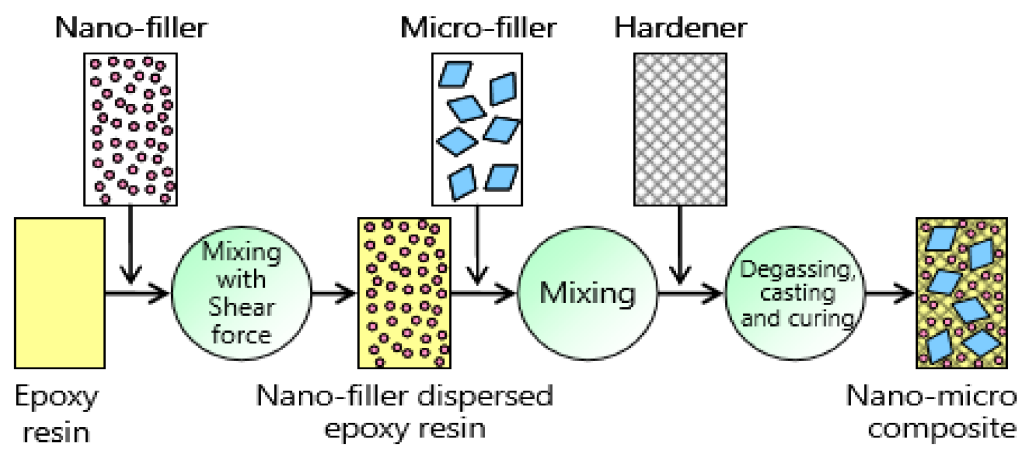

Figure 1. Scheme for the preparation of epoxy micro-nanocomposites [30].

\subsection{Aging Procedure}

The test epoxy specimens were subjected to gamma-ray irradiation through a ${ }^{60} \mathrm{Co}$ radiation source in air ambience with a dosage rate of $660 \mathrm{~Gy} / \mathrm{h}$ up to total dosage of $4 \mathrm{kGy}$ and $8 \mathrm{kGy}$. Hence, three test specimens unaged, $4 \mathrm{kGy}$ and $8 \mathrm{kGy}$ gamma irradiated specimens were selected for analysis. Epoxy specimens have been immersed in deionized water at $90^{\circ} \mathrm{C}$ and room temperature for $240 \mathrm{~h}$, respectively. The percentage weight gain of epoxy specimens can be calculated as shown in (1).

$$
P(t)=\frac{W(t)-W_{O}}{W_{O}} \times 100 \%
$$

where $W_{O}$ is the mass of unaged specimen, $W(t)$ is the mass of test specimen at an ageing time $t$, and $P(t)$ is the percentage weight gain of the epoxy sample at an aging time $t$. 
Figure 2 depicts the percentage weight gain of water aged test samples, aged at room temperature and at $90^{\circ} \mathrm{C}$ separately. The weight gain becomes almost constant by $240 \mathrm{~h}$. The initial water diffusion rate and the final weight gain are higher for $90{ }^{\circ} \mathrm{C}$ water aged specimens compared to room temperature water aged specimens. The water diffusion coefficient can be determined as shown in (2) [30].

$$
D=\frac{\pi L_{0.5}^{2}}{64 t_{0.5}}
$$

where $L$ is the thickness of sample, $D$ is the diffusion coefficient, and $t_{0.5}$ is time required for the specimen to reach half of the steady state value of percentage weight gain.

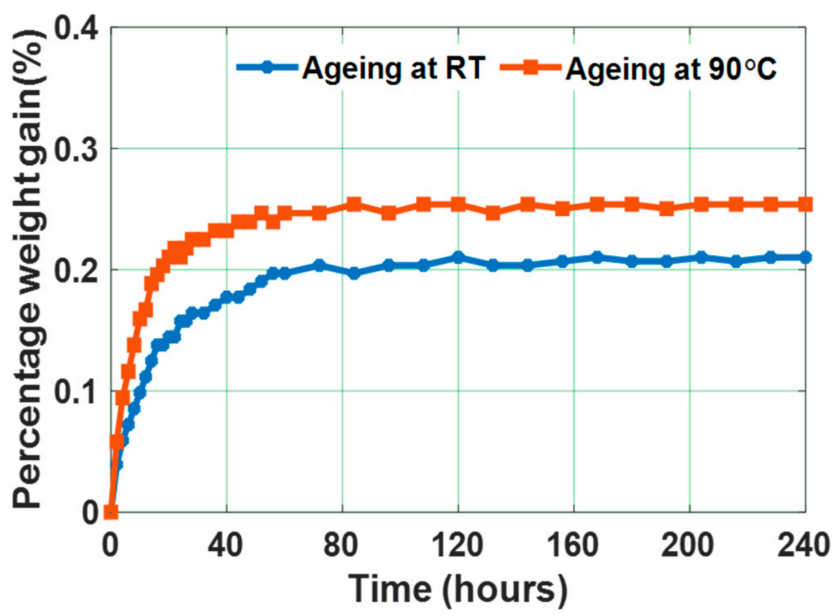

Figure 2. Percentage weight gain of epoxy samples subjected to water ageing at room temperature (RT) and $90{ }^{\circ} \mathrm{C}[30]$.

The water diffusion coefficients of the test samples aged in deionized water at room temperature and $90^{\circ} \mathrm{C}$ are $4.97 \times 10^{-12} \mathrm{~m}^{2} \mathrm{~s}^{-1}$ and $7.74 \times 10^{-12} \mathrm{~m}^{2} \mathrm{~s}^{-1}$, respectively. Diffusion of water is dependent on the available free volume in the form of molecular sized holes in the polymer matrix and also the affinity of polymer towards water. This available free volume in turn depends on the morphology, crosslink density, and polymer structure. The water affinity of polymer depends on the hydrogen bonding sites to be present along the polymeric chains, to develop attractive forces between polymer and water molecules [39]. During water aging at $90^{\circ} \mathrm{C}$, microstructural deformation may possibly take place in the bulk of the sample, because of its exposure to high temperatures [41]. Polymer crosslinking density gets affected by this, increasing the free volume. Due to this, water molecules diffuse more into the sample aged at $90{ }^{\circ} \mathrm{C}$ compared to the sample aged at room temperature. In addition, Huner et al. have indicated that the degradation induced due to water intake in composite specimens is more predominant at high temperatures [55]. These epoxy specimens were kept for drying for a period of $24 \mathrm{~h}$ after $240 \mathrm{~h}$ of water aging. Hence, three epoxy micro-nano composite specimens: Unaged specimen, water aged specimens at room temperature $(\mathrm{RT})$ and $90^{\circ} \mathrm{C}$, respectively, were finalized for further characterizations.

\subsection{Space Charge Measurement}

Figure 3 represents the experimental setup for the measurement of space charge adopting pulsed electro acoustic (PEA) method. In PEA method, when an electrical pulse is applied to the specimen, acoustic waves are produced at charge layers at both electrodespecimen interface and at internal charges. These acoustic signals are converted into electric signals by a piezo-electric transducer, which represents the charge distribution. This obtained electric signal after calibration gives the quantitative information about space charge density [56]. Techimp PEA System has been employed for space charge 
measurement. This experimental setup consists of a PEA Flat cell, a voltage pulse generator with voltage magnitude of 0-500 V, pulse width of $10 \mathrm{~ns}$ and frequency of $150 \mathrm{~Hz}$, a high voltage variable DC source in the range of $0-30 \mathrm{kV}$, a DC source of 18-24 V to supply the amplifiers, and an oscilloscope (Tektronix, $350 \mathrm{MHz}, 5 \mathrm{GS} / \mathrm{s}$ ). The test specimen used for the study is a flat type sheet material with dimensions $40 \times 40 \times 1 \mathrm{~mm}^{3}$.

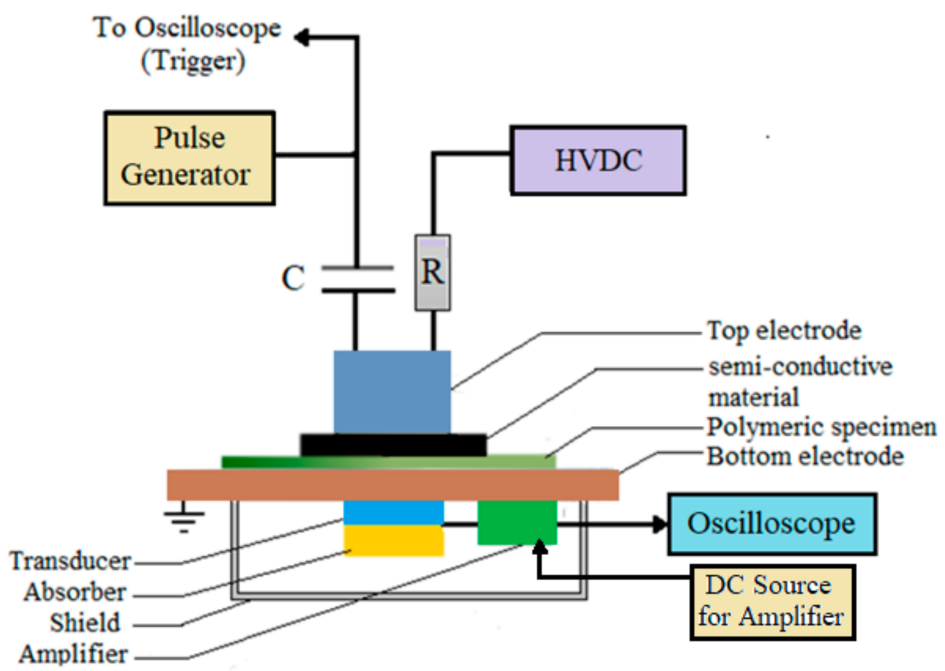

Figure 3. Pulsed electro acoustic (PEA) experimental setup of space charge measurement [30].

\section{Results and Discussion}

3.1. Impact of Gamma Irradiation on Space Charge Characteristics of Epoxy Micro-Nano Composites

Difference in the current density in the bulk volume of a dielectric material under the applied field conditions results in the formation of space charge [57]. Figure 4 represents the space charge profiles of epoxy specimens under various positive DC electric fields. The presence of homo-charge is noticed in test specimens, near the vicinity of the electrodedielectric interface. The net space charge formation is dependent on processes such as charge injection/extraction and charge transportation. When the rate of charge injection is higher than the rate of charge transportation, it results in the formation of homo-charge. The amount of homo-charge formed near the electrode-dielectric interface increases with increase in the magnitude of applied electric field. According to the Schottky process, the charge carriers near the electrode-dielectric interface should overcome a potential barrier in order to enter into dielectric material [58]. The potential barrier decreases with the increase in the magnitude of applied electric field, making the charge injection process easier. Therefore, the amount of homo-charge formed near the interface tends to increase with increase in the applied electric field.

The magnitude of space charge accumulated at an applied electric field helps in understanding the extent of degradation of the test specimen. The mean magnitude of accumulated space charge density $q(E, t)$ in the specimen can be calculated as shown in (3) [57].

$$
q(E, t)=\frac{1}{x_{1}-x_{0}} \int_{x_{0}}^{x_{1}}\left|q_{p}(x, t ; E)\right| d x
$$

where $x_{0}$ and $x_{1}$ represent the position of the electrodes (induced charges at the electrodes are neglected), and $q_{p}(x, t ; E)$ is the charge density at position $x$, time $t$, and electric field applied $E$. 


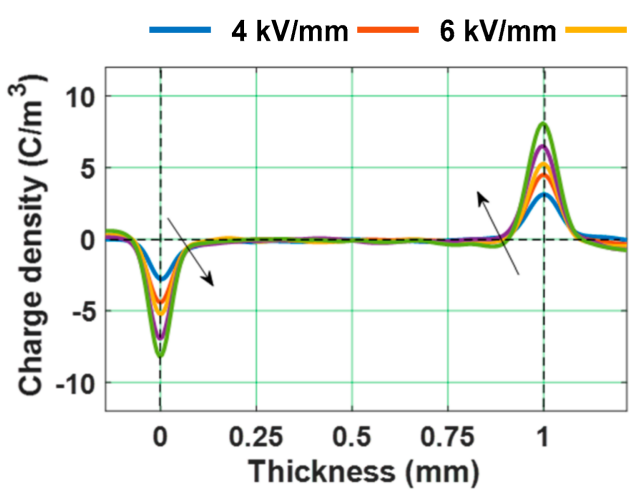

(a)

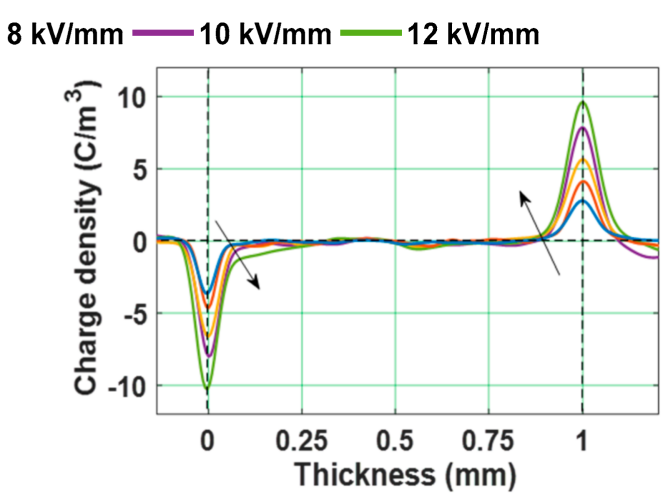

(b)

Figure 4. Variation in space charge density under different applied electric fields in (a) unaged and (b) 8 kGy gamma irradiated epoxy micro-nano composites [29].

The threshold for space charge accumulation $\left(E_{T}\right)$ and rate of space charge accumulation $(b)$ can be calculated from the plot depicting average space charge density versus electric field applied (Figure 5). The parameters $E_{T}$ and $b$ are not dependent on the applied electric field and the time, provided that the average space charge density is measured at the quasi-steady state condition of space charge accumulation [59]. The average charge density just after one hour of poling time at each electric field is considered for calculating $E_{T}$. The slope of the fitted line above the threshold point $\left(E_{T}\right)$ of each sample in Figure 5, provides the parameter $b[59]$. The parameter $E_{T}$ is marginally higher for unaged sample rather than gamma irradiated samples (Table 1 ). This indicates that the field above which a significant space charge accumulation occurs tends to decrease with dosage of gamma irradiation. The parameter $b$ tends to increase with increase in dosage of gamma irradiation, indicating that a relatively higher amount of space charge accumulation occurs in gamma irradiated samples than unaged samples, at electric fields higher than $E_{T}$. Therefore, the decrease in $E_{T}$ and increase in $b$ with increase in dosage of gamma irradiation reflects the possibility of early degradation of the properties of the insulating material leading to premature breakdown.

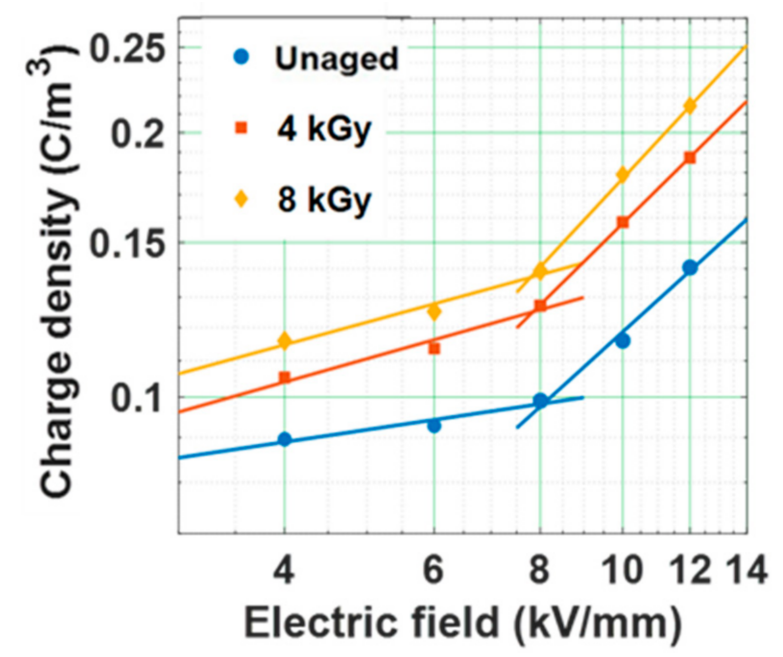

Figure 5. Average space charge density as a function of applied electric field in gamma irradiated samples [29]. 
Table 1. Parameter values of unaged and gamma irradiated samples [29].

\begin{tabular}{|c|c|c|}
\hline Specimen & $E_{T}\left(\mathrm{kV} / \mathrm{mm}^{-1}\right)$ & $b\left(\mu C V^{-1} m^{-2}\right)$ \\
\hline Unaged & 8.08 & 0.876 \\
\hline 4 kGy & 7.88 & 0.952 \\
\hline 8 kGy & 7.83 & 1.038 \\
\hline
\end{tabular}

Since the value of $E_{T}$ is noticed to be around $8 \mathrm{kV} / \mathrm{mm}$, an electric field of $10 \mathrm{kV} / \mathrm{mm}$ is considered for further analysis. The space charge profiles of test samples at different instants of poling time, under $10 \mathrm{kV}$ positive DC voltage are represented in Figure 6. An increment in the homo-charge accumulation with respect to poling time, near the electrode-dielectric interface, is observed. Figure 7 depicts the space charge characteristics of epoxy samples during depoling. The charge induced at the electrode-specimen interface is reduced instantly just after decreasing the applied voltage to zero, leaving the accumulated homo-charge.

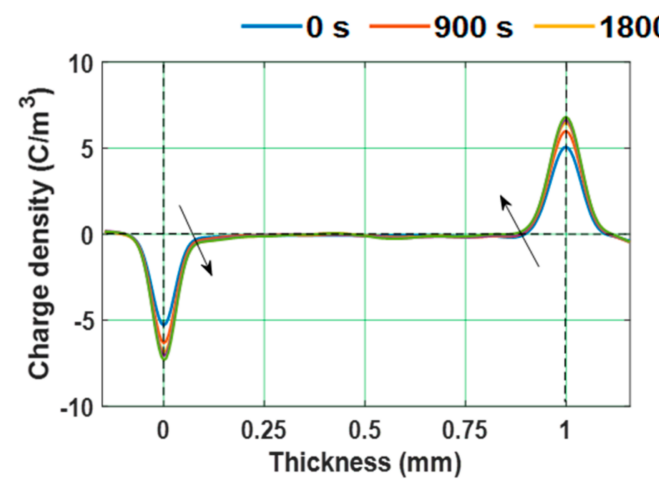

(a)

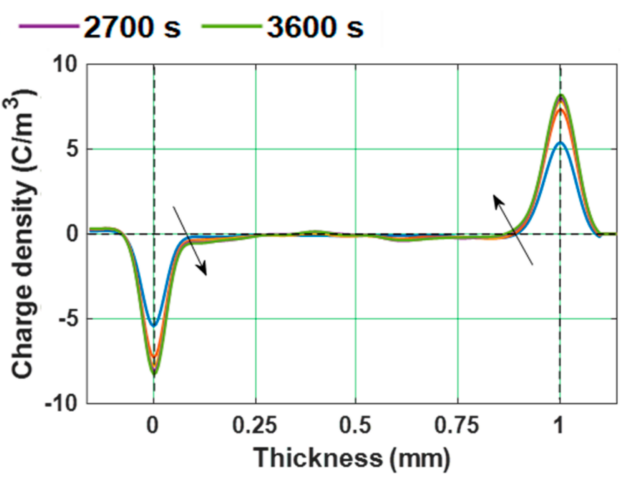

(b)

Figure 6. Space charge distribution during poling in (a) unaged and (b) $8 \mathrm{kGy}$ gamma irradiated epoxy micro-nano composites under $10 \mathrm{kV}$ positive DC voltage [29].

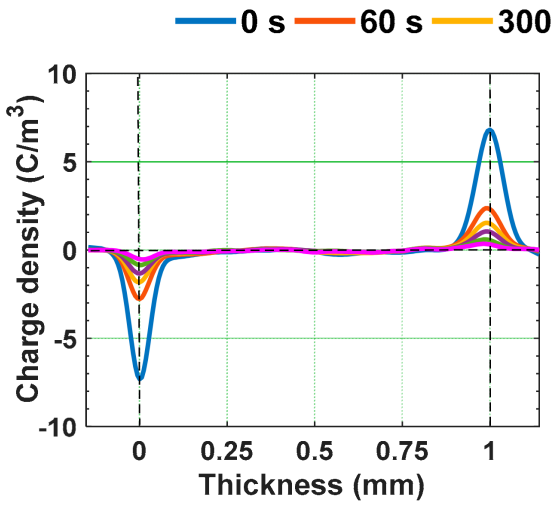

(a)

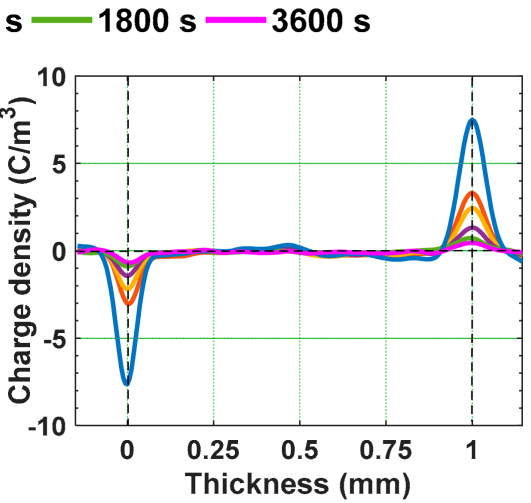

(b)

Figure 7. Space charge distribution during depoling of (a) unaged and (b) 8 kGy gamma irradiated epoxy micro-nano composites after reduction of $10 \mathrm{kV}$ positive DC voltage [29].

The magnitude of charge density of the test samples at poling and depoling periods is depicted in Figure 8. The magnitude of space charge density is higher for gamma irradiated samples compared to unaged samples (Figure 8a). Chen et al. studied the space charge behavior of gamma irradiated polyethylene under various radiation environments and have indicated that the increase in the space charge accumulation of the gamma irradiated samples compared to unaged samples is more when irradiated in air ambience. Meanwhile, 
only a small amount of space charge accumulation is noticed in specimens irradiated in both nitrogen and vacuum environments [50]. Similar characteristics are noticed in the test specimens with an increase in the average space charge density with dosage of irradiation in air ambience (Figure 8a). Internal charge carriers tend to form when they gain sufficient energy to escape from valence band to conduction band. This energy to the charge carriers can be obtained by thermal, electrical, or radio-active phenomenon. Therefore, the formation of internal charge carriers or free radicals in the bulk of the gamma irradiated samples due to chain scissions and oxidation phenomena results in the increment of average space charge density.

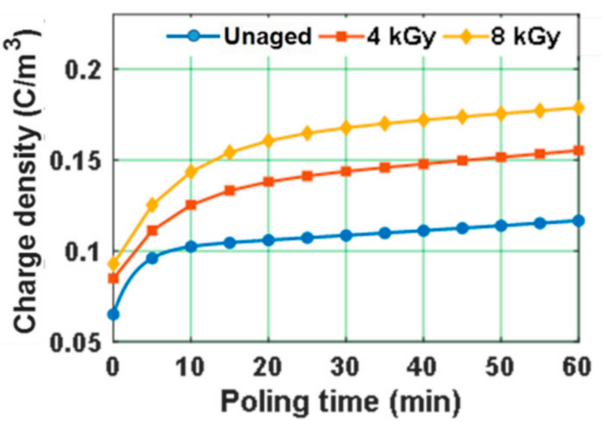

(a)

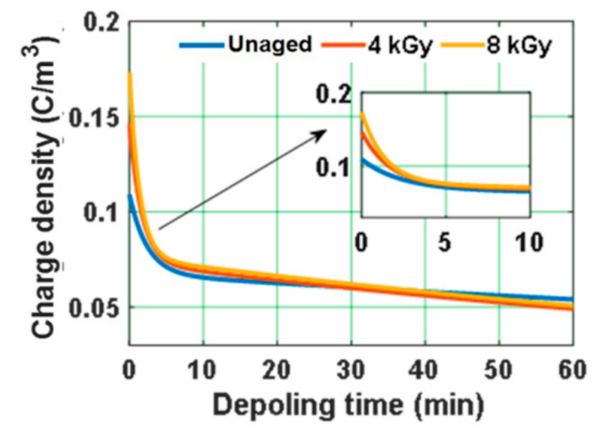

(b)

Figure 8. Average space charge density of unaged and gamma irradiated samples during (a) poling time and (b) depoling time [29].

The charge decay during depoling is faster in gamma irradiated samples than unaged ones (Figure 8b). The trapping and de-trapping phenomena are mostly related to the charge trap distribution in terms of energy depths. The charge traps in general tend to have several discrete energy depths or energy levels. However, to simplify, it is assumed that the traps are uniformly distributed across the bulk of sample and possess only two trap energy levels, i.e., shallow trap and deep trap [60]. For further simplification, the charge injection process is considered to follow the Schottky process of charge injection, and the current tends to increase exponentially with the electric field applied and tends to decay exponentially during the depoling time. Therefore, the charge decay curves during depoling were modelled as double exponential function as represented in (4).

$$
n(t)=n_{1} e^{-a x}+n_{2} e^{-b x}
$$

where summation of $n_{1}$ and $n_{2}$ gives the magnitude of space charge density just before depoling, and $a$ and $b$ are the exponential factors which indicate the charge decay rates.

The parameters determined by modelling the magnitude of space charge density during depoling time are tabulated in Table 2. Zhou et al. have stated that the parameters $a, b, n_{1}$, and $n_{2}$ are related to microstructure of the specimen and any changes in these parameters will affect the aging process that takes place in the specimen [60]. Figure 9 depicts the magnitude of initial charge density just before depoling, and the mean lifetime of the charge decay curves that are determined from the parameters represented in Table 2. The charge decay rate " $b$ " is order of $10^{-4}$, which reflects that the charge decay corresponding to the part $n_{2}$ is almost negligible when compared to charge decay of the part $n_{1}$. Hence, to compare the charge decay parameters of unaged and gamma irradiated specimens during depoling time, only the charge decay rate " $a$ " is considered for calculating mean lifetime of charge decay. The mean lifetime of the charge decay is lesser in gamma irradiated epoxy samples compared to unaged sample. Lower mean life time indicates that the charge transportation rate in the bulk of the material is higher. The transportation of charge carriers depends on the depth of the charge trapping sites. Chen et al. have indicated that the carbonyl groups concentration tends to increase with radiation dose 
and further the carbonyl groups generate a shallow trap that can possibly assist charge transport [61]. Therefore, the faster space charge decay in the gamma irradiated samples during depoling, could be due to the formation of a relatively higher number of shallow traps, which tends to increase the rate of charge carrier transportation.

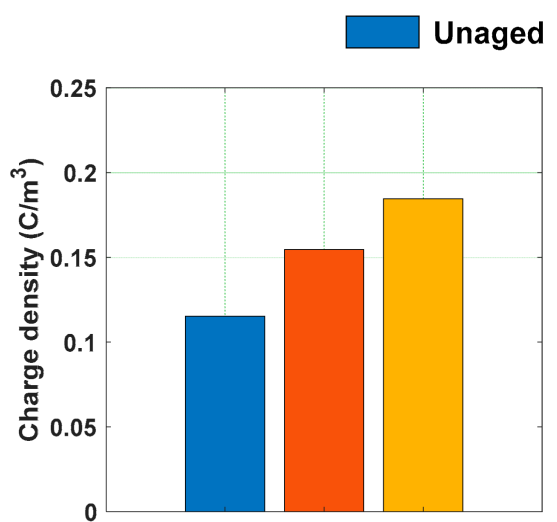

(a)

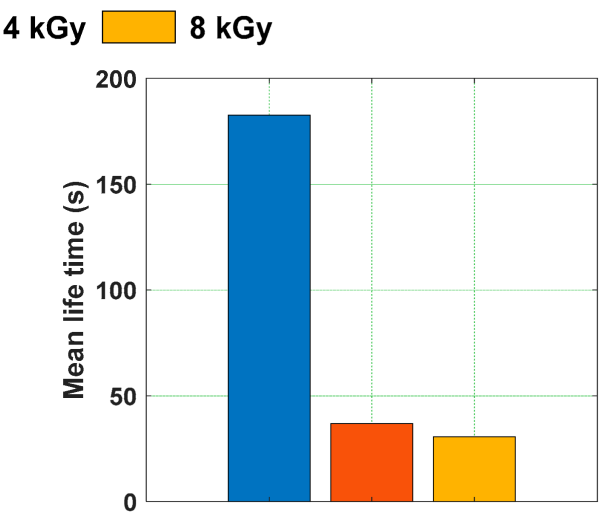

(b)

Figure 9. (a) Initial charge density just before depoling and (b) mean lifetime of space charge decay of gamma irradiated samples.

Table 2. Modelling parameters of mean magnitude of charge density during depoling time.

\begin{tabular}{ccccc}
\hline Specimen & $\boldsymbol{n}_{\mathbf{1}}$ & $\boldsymbol{a}$ & $\boldsymbol{n}_{\mathbf{2}}$ & $\boldsymbol{b}$ \\
\hline Unaged & 0.0502 & 0.00548 & 0.0649 & $2.26 \times 10^{-5}$ \\
$4 \mathrm{kGy}$ & 0.1190 & 0.02708 & 0.0356 & $2.37 \times 10^{-4}$ \\
$8 \mathrm{kGy}$ & 0.1288 & 0.03261 & 0.0557 & $2.25 \times 10^{-4}$ \\
\hline
\end{tabular}

The epoxy micro-nano composites were subjected to $10 \mathrm{kV} / \mathrm{mm}$ positive DC field for $1800 \mathrm{~s}$ before the polarity reversal, and after polarity reversal, the samples were subjected to $10 \mathrm{kV} / \mathrm{mm}$ negative DC field for $1800 \mathrm{~s}$. In between, the voltage polarity reversal time was maintained as $40 \mathrm{~s}$. The space charge density and electric field distribution profiles of unaged and gamma irradiated epoxy samples during poling time and polarity reversal period are depicted in Figures 10 and 11.

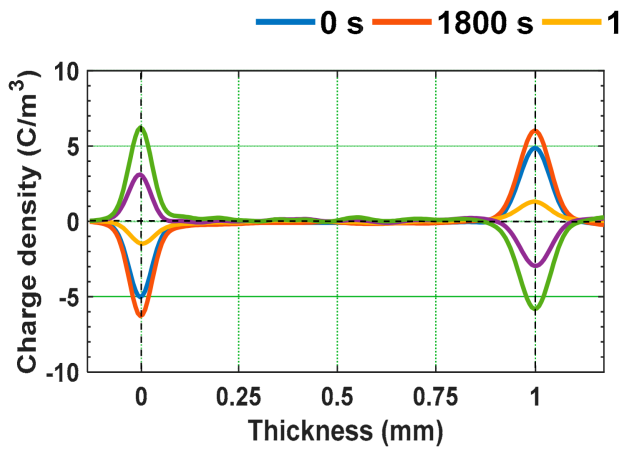

(a)
$1820 \mathrm{~s}-1840 \mathrm{~s}-3640 \mathrm{~s}$

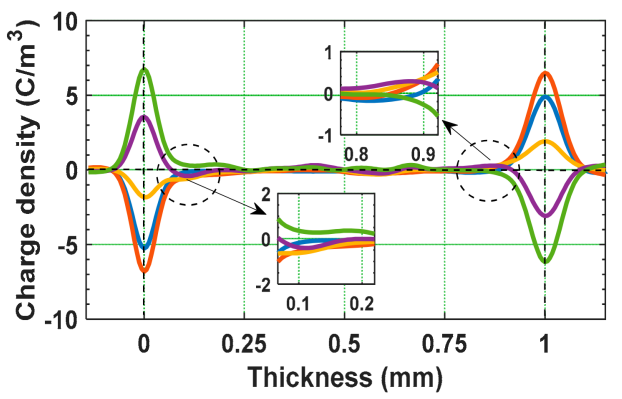

(b)

Figure 10. Space charge distribution under polarity reversal from positive to negative DC field stress in (a) virgin and (b) $8 \mathrm{kGy}$ gamma irradiated specimens [29].

The accumulated homo-charge before voltage polarity reversal (at $1800 \mathrm{~s}$ ) in Figure 10b is retained during the polarity reversal period (1800-1840 s). The field distribution is modified due to this retained space charge and this will further affect the space charge 
distribution after voltage polarity reversal. After the polarity reversal phenomenon, the accumulated space charge due to opposite polarity field stress first reduces the retained charge and then cancels it. Then, finally, the space charge with reversed polarity is formed at the same position by the end of poling period after reversal (at $3640 \mathrm{~s}$ ). Wang et al. have indicated that the homo-charges injected before polarity reversal will remain in the insulating material as hetero-charges after the polarity reversal of DC field. They have indicated that the portion of charge retained after polarity reversal could possibly migrate under reversed electric field or get neutralized by the electrons injected from cathode [48]. Similar behavior is observed from Figure 10b, depicting the space charge density of $8 \mathrm{kGy}$ irradiated sample during voltage polarity reversal.

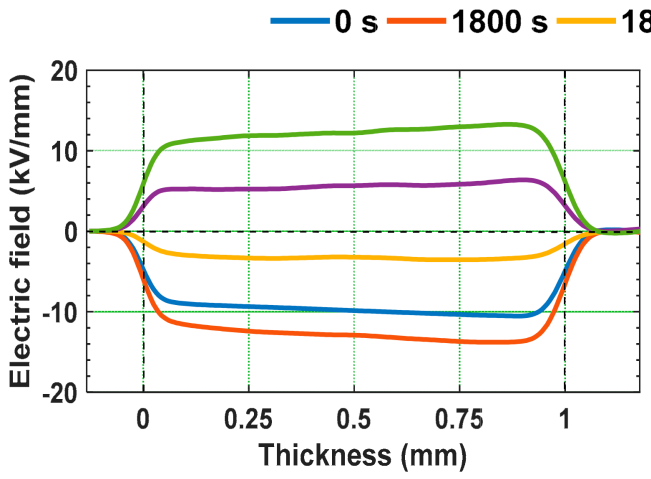

(a)
$1820 s-1840 s-3640 s$

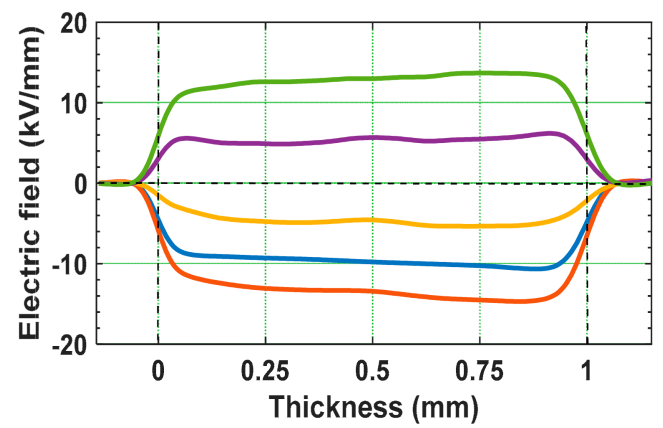

(b)

Figure 11. Electric field distribution under polarity reversal from positive to negative DC field stress in (a) virgin and (b) $8 \mathrm{kGy}$ gamma irradiated specimens [29].

Space charge presence in a dielectric can possibly lead to local electric field distortion, due to which the dielectric will experience higher electric fields than the applied electric field, in some of the regions in the bulk of the specimen. The extent of electric field distortion can be quantified by calculating the electric field enhancement factor [62]. It is represented as shown in (5).

$$
F=\frac{E-E_{a}}{E_{a}} \times 100
$$

where $E_{a}$ represents the electric field applied $(\mathrm{kV} / \mathrm{mm}), \mathrm{E}$ is the maximum electric field in the bulk of the specimen $(\mathrm{kV} / \mathrm{mm})$, and $\mathrm{F}$ represents the field enhancement factor $(\%)$.

The electric field enhancement factor of unaged and gamma irradiated samples just before polarity reversal i.e., at $1800 \mathrm{~s}$ and after a poling time of $1800 \mathrm{~s}$ from polarity reversal i.e., at 3640 s, can be depicted in Figure 12. The electric field enhancement tends to increase with gamma radiation dose, before and after the voltage polarity reversal phenomenon.

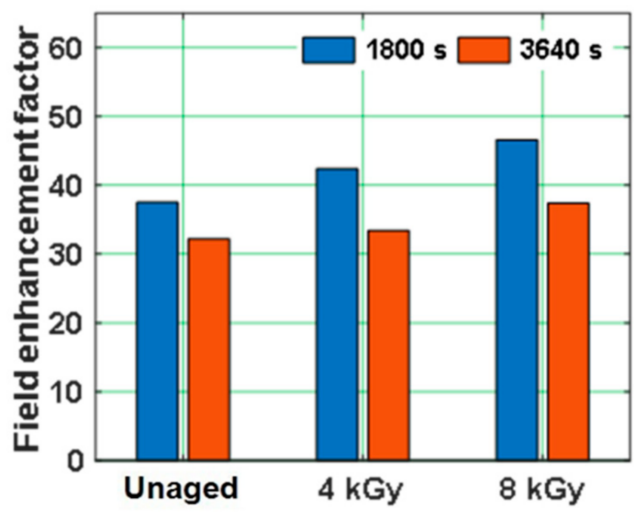

Figure 12. Field enhancement factor of unaged and gamma irradiated epoxy nanocomposites [29]. 


\subsection{Impact of Water Aging on Space Charge Characteristics of Epoxy Micro-Nanocomposites}

The magnitude of space charge accumulation is a function of applied electric field applied across the sample. The plot depicts the dependance of the magnitude of space charge density accumulated (calculated from (3)) and applied electric field (Figure 13). The threshold electric field $\left(E_{T}\right)$ of the test samples tends to reduce significantly after water aging (Table 3). The rate of space charge accumulation $(b)$ is noticed to increase after water aging. Decrement in the value of $E_{T}$ with water ageing, confirms the decrease in the potential barrier (as per the Schottky process of charge injection [58]), resulting in easier charge injection process. Hence, the reduction in $E_{T}$ and increment in parameter $b$ after water aging leads to the early deterioration of the epoxy specimens.

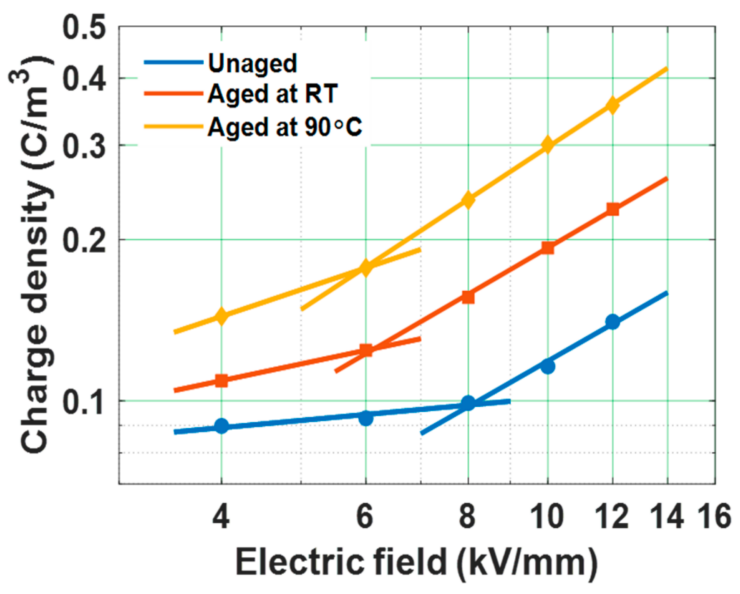

Figure 13. Relation between mean magnitude of space charge density and applied electric field of water aged samples [30].

Table 3. Space charge parameter values of unaged and water aged samples [30].

\begin{tabular}{|c|c|c|}
\hline Specimen & $E_{T}\left(\mathrm{kV} / \mathrm{mm}^{-1}\right)$ & $b\left(\mu C V^{-1} \mathrm{~m}^{-2}\right)$ \\
\hline Unaged & 8.03 & 0.875 \\
\hline Aged at RT & 6.26 & 0.891 \\
\hline Aged at $90^{\circ} \mathrm{C}$ & 5.94 & 1.008 \\
\hline
\end{tabular}

Since, the value of $E_{T}$ of the water aged samples is lesser than $8 \mathrm{kV} / \mathrm{mm}, 10 \mathrm{kV} / \mathrm{mm}$ is considered as applied electric field. Homo-charge formation is observed in water samples, indicating that the charge injection rate is more than the charge transportation rate [58]. Homo-charge accumulation is increased more significantly in water aged samples compared to unaged samples (Figure 14). Figure 15 depicts the space charge characteristics of water aged epoxy samples at different instants of depoling time. The charges induced at the electrode-sample interface has reduced as soon as applied voltage is decreased to zero, leaving only the space charge. The magnitude of space charge density in the water aged samples during both the poling and depoling periods are represented in Figure 16. The magnitude of charge density during poling period is higher in water aged samples compared to unaged sample (Figure 16a). Fabiani et al. have stated that the increment in the amount of water absorption into the volume of the sample results in the increment of space charge accumulation [63]. The potential barrier of charge injection at the electrodespecimen interface tends to decrease with the diffusion of water molecules, allowing more amount of charge to inject into the volume of the specimen [63]. Therefore, the mean magnitude of accumulated charge density is directly in proportion to the amount of water diffusion into the specimen. 


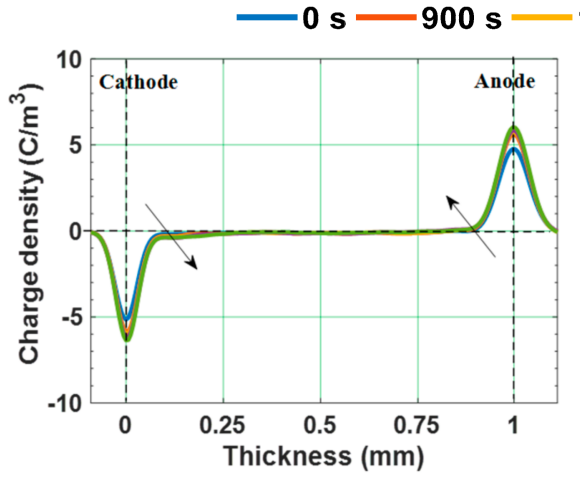

(a)

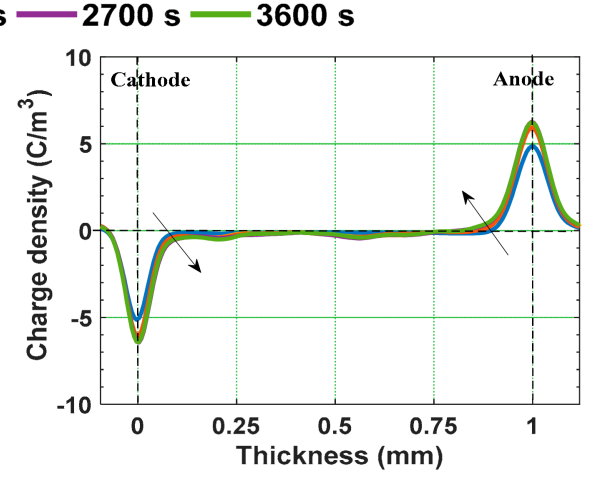

(b)

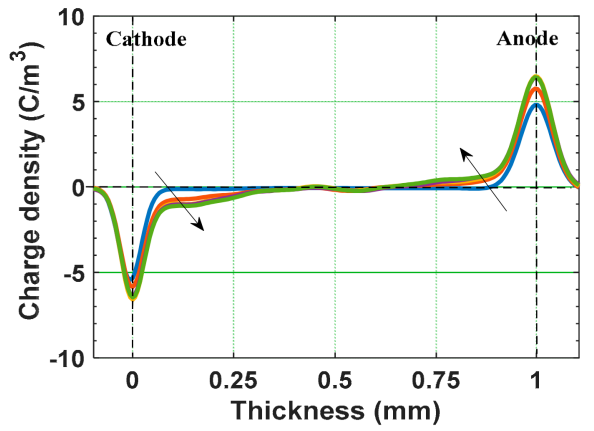

(c)

Figure 14. Space charge profiles during poling in (a) unaged, (b) water aged sample at RT, and (c) water aged sample at $90^{\circ} \mathrm{C}[30]$.

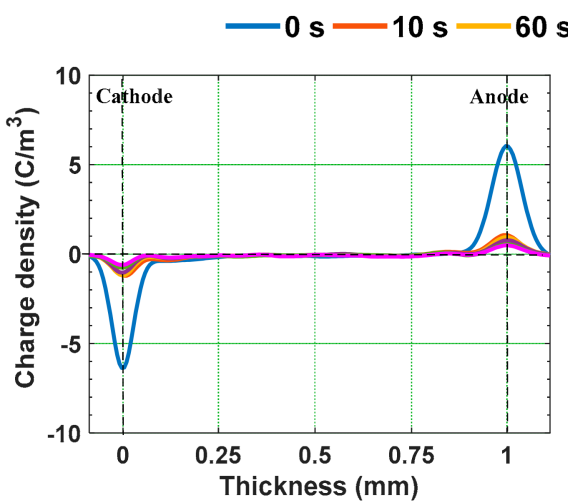

(a)

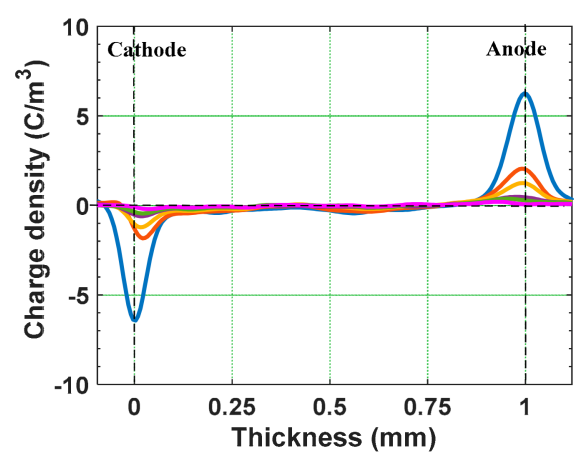

(b)

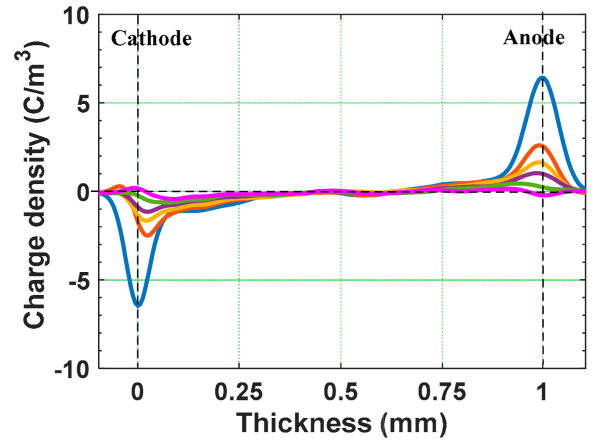

(c)

Figure 15. Space charge profiles during depoling in (a) unaged, (b) water aged sample at RT, and (c) water aged sample at $90^{\circ} \mathrm{C}[30]$. 


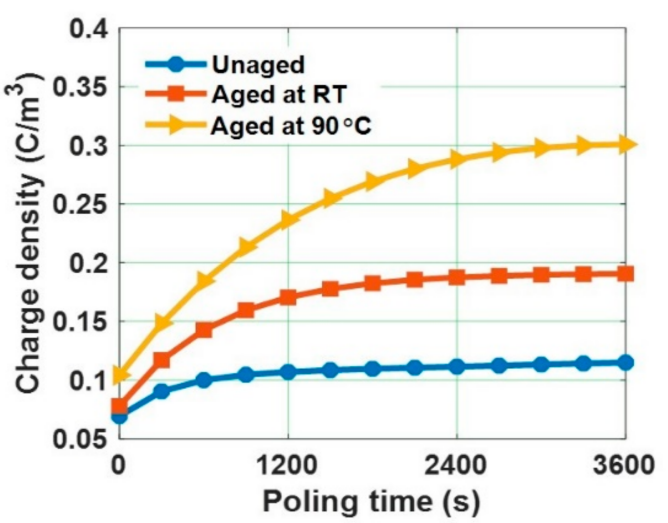

(a)

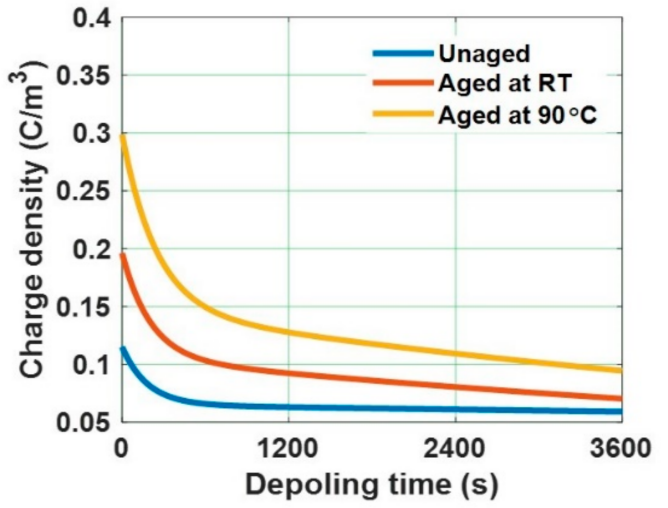

(b)

Figure 16. Mean value of absolute space charge density in water aged samples during (a) poling time and (b) depoling time [30].

The space charge decay curves during depoling period were modelled with a double exponential function as represented in (4). The parameters obtained by modelling the magnitude of space charge density have been tabulated in Table 4 . Figure 17 shows the magnitude of initial charge density just before depoling period and the mean lifetime of the space charge decay curves calculated from the parameters represented in Table 4. The mean lifetime of the space charge decay is more in $90{ }^{\circ} \mathrm{C}$ water aged samples, followed by the room temperature water aged sample and the unaged sample, respectively. The charge carriers that enter into the bulk of the sample through charge injection are trapped by the localized states, which originate due to crystal defects, matrix-filler interface, and catalyst residues [64]. The microstructural deformation in the water aged samples at high temperatures will lead to the increment of localized trapping sites resulting in the reduction of the space charge decay rate.

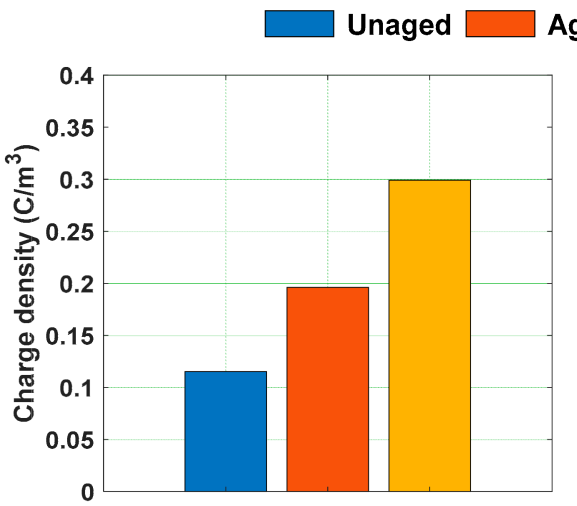

(a)

\section{Aged at RT $\square$ Aged at $90^{\circ} \mathrm{C}$}

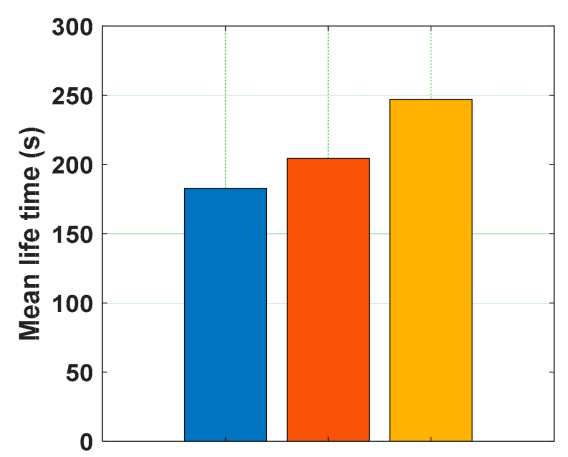

(b)

Figure 17. (a) Initial charge density just before depoling and (b) mean lifetime of space charge decay of water aged samples [30].

Table 4. Modelling parameters of magnitude of charge density during depoling time [30].

\begin{tabular}{ccccc}
\hline Specimen & $n_{\mathbf{1}}$ & $\boldsymbol{a}$ & $n_{\mathbf{2}}$ & $\boldsymbol{b}$ \\
\hline Unaged & 0.0502 & 0.00548 & 0.0649 & $2.26 \times 10^{-5}$ \\
Aged at RT & 0.0908 & 0.00489 & 0.1053 & $11.23 \times 10^{-5}$ \\
Aged at $90^{\circ} \mathrm{C}$ & 0.1524 & 0.00405 & 0.1465 & $12.21 \times 10^{-5}$ \\
\hline
\end{tabular}

The water aged epoxy specimens were subjected to voltage polarity reversal, by maintaining the polarity reversal time and voltage same as that of the polarity reversal phe- 
nomenon performed for gamma irradiated specimens mentioned above. Figures 18 and 19 represent the space charge density and electric field distribution of water aged epoxy samples. Similar to that of gamma irradiated specimens under polarity reversal, some portion of accumulated homo charge in water aged before polarity reversal is remained after the change in the voltage polarity also. It is because the polarity reversal time is lesser than the time required for the accumulated space charge to decay. The remained charge after polarity reversal acts as hetero-charge and tends to alter the local electric field distribution [48]. This can either increase or decrease the electric field, depending on the type of the space charge accumulated. Homo-charge accumulation near the electrode-specimen interface reduces the local electric field, whereas the hetero-charges enhance the local electric field. The retained homo-charge in the water aged epoxy specimens, just after polarity reversal i.e., $1840 \mathrm{~s}$, acts as hetero-charge, enhancing the local electric field near the electrode-sample interface. This electric field distortion can be quantified by calculating the electric field enhancement factor as shown in (5). The electric field enhancement factor of water aged specimens at the instant of $1800 \mathrm{~s}$ and $3640 \mathrm{~s}$ is represented in Figure 20. The electric field enhancement factor is higher in the $90^{\circ} \mathrm{C}$ water aged sample compared to the water aged sample at room temperature. The water aged samples are subjected to higher field distortion than unaged samples. This higher field distortion in $90^{\circ} \mathrm{C}$ water aged sample can possibly lead to the reduction in the insulator reliability and life span compared to unaged one.

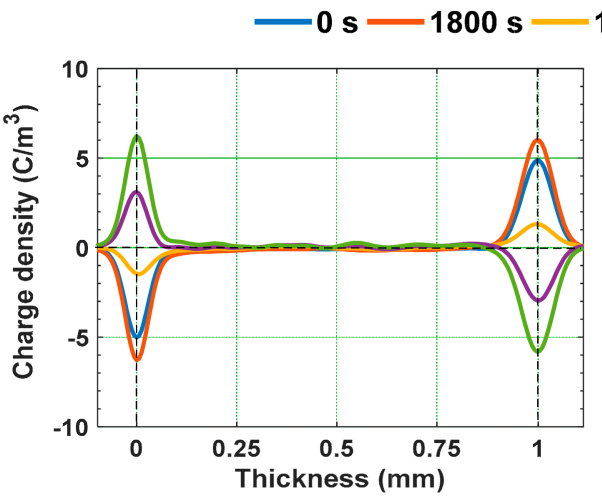

(a)

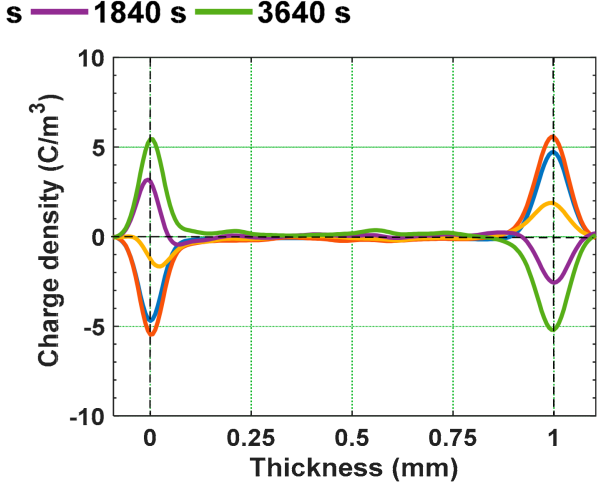

(b)

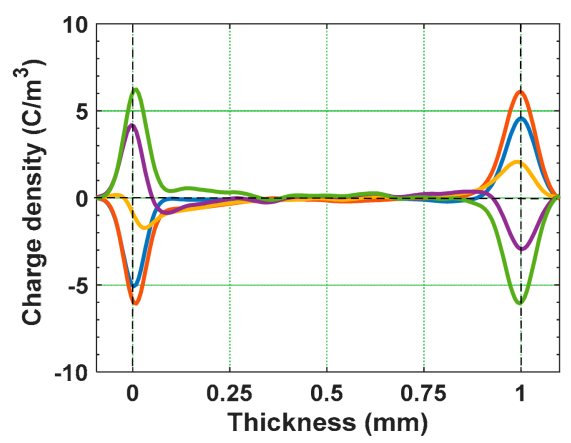

(c)

Figure 18. Space charge characteristics under voltage polarity reversal in (a) unaged specimen, (b) water aged specimen at RT, and (c) water aged specimen at $90^{\circ} \mathrm{C}$ [30].

\subsection{Comparitive Study on the Impact of Gamma Irradiation and Water Aging of Space Charge Characteristics of Epoxy Micro-Nanocomposites}

Homo-charge formation due to charge injection phenomenon has been noticed in the space charge profile of the unaged epoxy micro-nano composite specimen. This homocharge formation is marginally increased in case of gamma irradiated samples than unaged sample. Whereas a significant increment in the formation of homo-charge near sampleelectrode interface is noticed in water aged samples compared to the unaged sample. 
Moreover, at high temperature, where the water diffusion coefficient is higher than the diffusion coefficient at room temperature, the charge accumulation is observed to be higher. The mean magnitude of accumulated space charge density also reflected the same trend. In polymeric composite samples, incomplete dangling chain ends that originate near matrixfiller interfacial region due to catalyst residues, crystal defects, and aging mechanisms results in increment of localized trapping sites [64]. With aging mechanism, due to the deterioration of the molecular structure of the sample, the number of localized trapping sites increases, eventually resulting in higher space charge accumulation. The amount of charge density accumulated tends to increase with increase in the magnitude of DC applied electric field in all the test conditions. The threshold electric field $\left(E_{T}\right)$ tends to decrease and rate of space charge accumulation $(b)$ increases with increase in gamma irradiation dose as well as increase in diffusion coefficient of water. Significant reduction parameter $E_{T}$ is observed in water aged samples and only a marginal reduction in $E_{T}$ is observed with gamma irradiated samples.

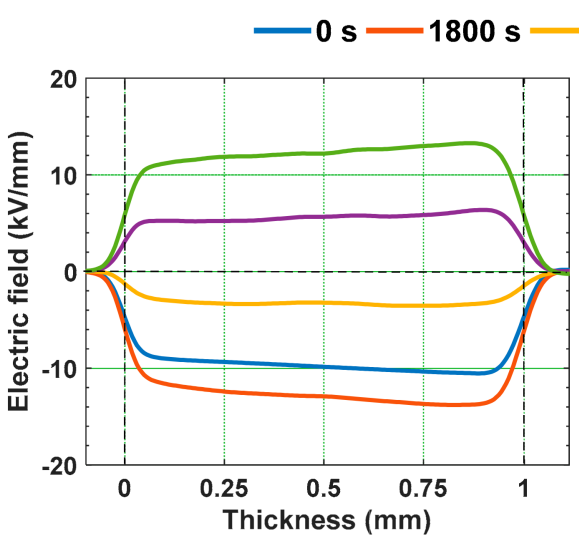

(a)

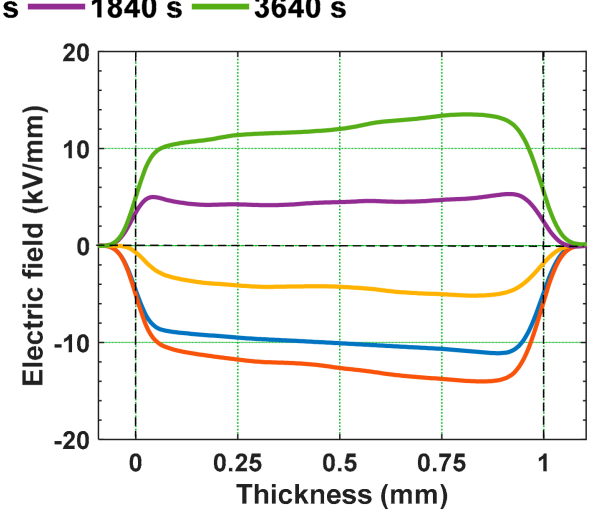

(b)

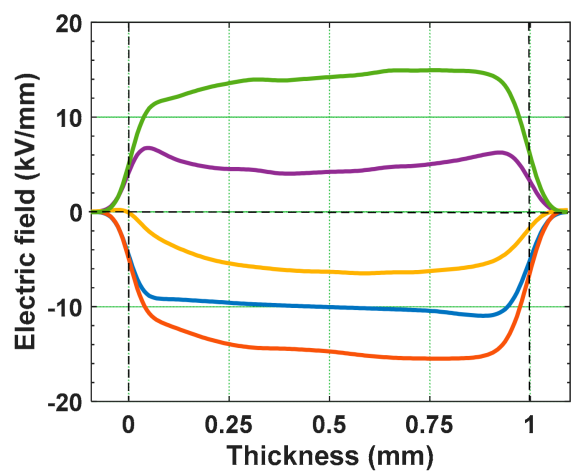

(c)

Figure 19. Electric field characteristics under voltage polarity reversal in (a) unaged specimen, (b) water aged specimen at RT, and (c) water aged specimen at $90^{\circ} \mathrm{C}$ [30].

One significant observation noticed form the comparison of two different aging procedures is that the decay rate of the accumulated space charge is higher in gamma irradiated epoxy samples compared to the unaged sample, whereas the space charge decay rate has reduced after water aging. The transportation of charge carriers is influenced by the depth of the charge trapping sites. The formation of carbonyl groups due to radiation-induced chemical reactions generate a tend to increase shallow trap density assisting charge transport, further leading to increased charge decay rate. The microstructural deformation in the water aged samples at high temperatures will lead to the increase of localized trapping sites resulting in the lowering the space charge decay rate. 


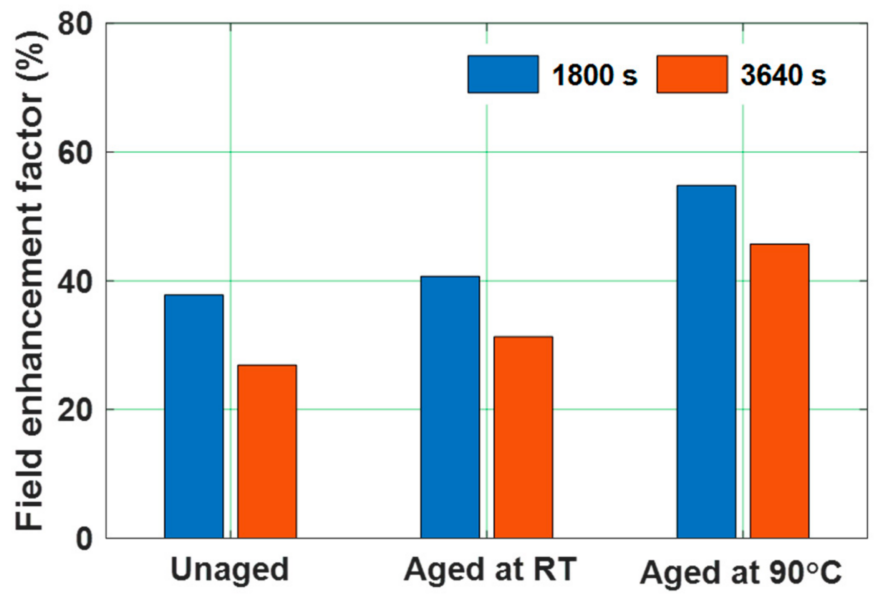

Figure 20. Field enhancement factor of unaged and water aged specimens [30].

Space charge profile of all the test samples during voltage polarity reversal reflected a portion of homo-charge accumulated before polarity reversal remained as hetero-charge just after polarity reversal. This remaining charge led to the distortion of local electric field. The electric field enhancement factor of aged samples tends to increase with the increase in radiation dose as well as diffusion coefficient, indicating aged samples are subjected to higher field distortion. This higher field distortions in aged epoxy samples minimizes the reliability and life span of the insulating material [65]. Hence, the field enhancement during the polarity reversal phenomenon is influenced by the pre-existing space charge (space charge accumulated just before polarity reversal) [66].

\section{Conclusions and Future Scope}

Epoxy nanocomposites are the most promising family of materials gaining much attention for the past few decades, because of their unique feature in achieving the desired properties in wide range of applications. Recent studies have proved that the addition of micro-silica particles to base epoxy matrix have successfully enhanced the mechanical properties of epoxy micro composites. Reinforcement of small wt.\% of nanofillers to these micro composites have enhanced electrical as well as thermal properties. Hence, the epoxy-micronano composites can possess the desired properties of both micro and nanocomposites.

Ion-trapping nano particles, which possess good oxidation resistance and high ion trapping ability, are being chosen as fillers along with silica micro fillers in epoxy micronano composite material for improving the reliability of electrical insulation structures. These epoxy micro-nano composites were subjected to different aging procedures (gamma irradiation and water aging) and their space charge behavior with respect to aging is analyzed. The important conclusions were arrived are as follows:

- Homo-charge formation due to charge injection phenomenon has been noticed in the space charge profile of both the unaged and aged epoxy micro-nano composite specimen.

- The threshold electric field $\left(E_{T}\right)$ tends to decrease and rate of space charge accumulation $(b)$ increases with increase in gamma irradiation dose as well as increment in diffusion coefficient of water

- Magnitude of accumulated space charge density is marginally increased in case of gamma irradiated samples than unaged sample, whereas a significant increment is noticed in water aged samples compared to unaged sample.

- The decay rate of the accumulated space charge is higher in gamma irradiated epoxy samples compared to unaged sample, whereas the space charge decay rate has reduced after water aging.

- Space charge profile of all the test samples during voltage polarity reversal reflected a portion of homo-charge accumulated before polarity reversal remained as heterocharge just after polarity reversal. 
- The electric field enhancement factor of aged samples tends to increase with increase in radiation dose as well as diffusion coefficient, indicating aged samples are subjected to higher field distortion

Finally, it can be concluded that the incorporation of ion-trapping nano particles in epoxy micro-nano composites for power apparatus application is truly promising. However, more research work needs to be carried out in future by diversifying the nanoparticles used and by subjecting these epoxy micro-nano composites to different aging conditions, in order to design a suitable material that can overcome major challenges due to aging conditions in industry and to be potentially applicable in future electrical insulation structures.

Author Contributions: All the authors have contributed equally in the present research work. All authors have read and agreed to the published version of the manuscript.

Funding: This research received no external funding.

Informed Consent Statement: Not applicable.

Data Availability Statement: The data that support the findings of this study are available from the corresponding author upon reasonable request.

Conflicts of Interest: The authors declare no conflict of interest.

\section{References}

1. Tanaka, T.; Imai, T. Advanced Nanodielectrics; Jenny Stanford Publishing: Singapore, 2017; ISBN 9781315230740.

2. Ellis, B. Chemistry and Technology of Epoxy Resins; Blackie Academic \& Professional: Glasgow, UK, 1993; pp. 1-332.

3. Bolon, D. Epoxy chemistry for electrical insulation. IEEE Electr. Insul. Mag. 1995, 11, 10-18. [CrossRef]

4. Zhong, S.; Dang, Z.; Zhou, W.; Cai, H. Past and future on nanodielectrics. IET Nanodielectrics 2018, 1, 41-47. [CrossRef]

5. Tanaka, T.; Imai, T. Advances in nanodielectric materials over the past 50 years. IEEE Electr. Insul. Mag. 2013, 29, 10-23. [CrossRef]

6. Cao, Y.; Irwin, P.C.; Younsi, K. The future of nanodielectrics in the electrical power industry. IEEE Trans. Dielectr. Electr. Insul. 2004, 11, 797-807. [CrossRef]

7. David, E.; Frechette, M. Polymer nanocomposites-major conclusions and achievements reached so far. IEEE Electr. Insul. Mag. 2013, 29, 29-36. [CrossRef]

8. Atif, R.; Shyha, I.; Inam, F. Mechanical, Thermal, and Electrical Properties of Graphene-Epoxy Nanocomposites-A Review. Polymers 2016, 8, 281. [CrossRef]

9. Saba, N.; Tahir, P.M.; Jawaid, M. A Review on Potentiality of Nano Filler/Natural Fiber Filled Polymer Hybrid Composites. Polymers 2014, 6, 2247-2273. [CrossRef]

10. Fu, S.-Y.; Feng, X.-Q.; Lauke, B.; Mai, Y.-W. Effects of particle size, particle/matrix interface adhesion and particle loading on mechanical properties of particulate-polymer composites. Compos. Part B Eng. 2008, 39, 933-961. [CrossRef]

11. Paul, S.; Sindhu, T.K. Effect of filler particle size on electric energy density of epoxy-aluminum nanocomposites. IEEE Trans. Dielectr. Electr. Insul. 2016, 23, 2786-2794. [CrossRef]

12. Pleşa, I.; Noţingher, P.V.; Schlögl, S.; Sumereder, C.; Muhr, M. Properties of Polymer Composites Used in High-Voltage Applications. Polymers 2016, 8, 173. [CrossRef]

13. Roy, M.; Nelson, J.; MacCrone, R.; Schadler, L.; Reed, C.; Keefe, R.; Zenger, W. Polymer nanocomposite dielectrics-The role of the interface. IEEE Trans. Dielectr. Electr. Insul. 2005, 12, 629-643. [CrossRef]

14. Šupová, M.; Martynková, G.S.; Barabaszová, K. Effect of Nanofillers Dispersion in Polymer Matrices: A Review. Sci. Adv. Mater. 2011, 3, 1-25. [CrossRef]

15. Sarathi, R.; Sahu, R.; Rajeshkumar, P. Understanding the thermal, mechanical and electrical properties of epoxy nanocomposites. Mater. Sci. Eng. A 2007, 445, 567-578. [CrossRef]

16. Suriati, G.; Mariatti, M.; Azizan, A. Effects of filler shape and size on the properties of silver filled epoxy composite for electronic applications. J. Mater. Sci. Mater. Electron. 2011, 22, 56-63. [CrossRef]

17. Guo, Y.; Du, B.X.; Liu, Y.; Tian, L. Tracking of epoxy/MgO nanocomposites under DC Stress. In Proceedings of the 2013 IEEE International Conference on Solid Dielectrics (ICSD), Bologna, Italy, 30 June-4 July 2013; pp. 884-887.

18. Sancaktar, E.; Bai, L. Electrically Conductive Epoxy Adhesives. Polymers 2011, 3, 427-466. [CrossRef]

19. Qiang, D.; Wang, Y.; Chen, G.; Andritsch, T. Dielectric properties of epoxy silica and boron nitride nanocomposites and moisture/temperature influences. IET Nanodielectr. 2018, 1, 48-59. [CrossRef]

20. Fothergill, J.C.; Nelson, J.K.; Fu, M. Dielectric properties of epoxy nanocomposites containing $\mathrm{TiO}_{2}, \mathrm{Al}_{2} \mathrm{O}_{3}$ and $\mathrm{ZnO}_{\text {fillers }}$ In Proceedings of the Annual Report-Conference on Electrical Insulation and Dielectric Phenomena, Boulder, CO, USA, 20 October 2004. 
21. Iyer, G.; Gorur, R.S.; Richert, R.; Krivda, A.; Schmidt, L.E. Dielectric properties of epoxy based nanocomposites for high voltage insulation. IEEE Trans. Dielectr. Electr. Insul. 2011, 18, 659-666. [CrossRef]

22. Zhang, S.; Zhang, H.; Peng, Z. Electrical properties of epoxy-based nanocomposites filled with graphene oxide. IEEE Electr. Insul. Mag. 2016, 31, 108-111.

23. Wang, Z.; Zhou, W.; Dong, L.; Sui, X.; Cai, H.; Zuo, J.; Chen, Q. Dielectric spectroscopy characterization of relaxation process in $\mathrm{Ni} /$ epoxy composites. J. Alloys Compd. 2016, 682, 738-745. [CrossRef]

24. Kim, H.; Jung, D.; Jung, I.; Cifuentes, J.; Rhee, K.; Hui, D. Enhancement of mechanical properties of aluminium/epoxy composites with silane functionalization of aluminium powder. Compos. Part B Eng. 2012, 43, 1743-1748. [CrossRef]

25. Imai, T.; Sawa, F.; Nakano, T.; Ozaki, T.; Shimizu, T.; Kozako, M.; Tanaka, T. Effects of nano- and micro-filler mixture on electrical insulation properties of epoxy based composites. IEEE Trans. Dielectr. Electr. Insul. 2006, 13, 319-326. [CrossRef]

26. Goyanes, S.N.; König, P.G.; Marconi, J.D. Dynamic mechanical analysis of particulate-filled epoxy resin. J. Appl. Polym. Sci. 2003, 88, 883-892. [CrossRef]

27. Tsekmes, I.A.; Morshuis, P.H.F.; Smit, J.J.; Kochetov, R. Enhancing the thermal and electrical performance of epoxy microcomposites with the addition of nanofillers. IEEE Electr. Insul. Mag. 2015, 31, 32-42. [CrossRef]

28. Mishra, P.; Gautam, R.; Vinu, R.; Sarathi, R. Understanding the water droplet initiated discharges on gamma irradiated silicone rubber insulation. Polym. Eng. Sci. 2019, 59, 182-191. [CrossRef]

29. Babu, M.S.; Sarathi, R.; Vasa, N.J.; Imai, T. Investigation on space charge and charge trap characteristics of gamma-irradiated epoxy micro-nano composites. High Volt. 2020, 5, 191-201. [CrossRef]

30. Babu, M.S.; Velmurugan, R.; Sarathi, R.; Imai, T. Influence of water ageing on variation in space charge and thermo-mechanical properties of epoxy micro-nano composites. IET Sci. Meas. Technol. 2021, 15, 44-60. [CrossRef]

31. Desai, B.M.A.; Mishra, P.; Vasa, N.J.; Sarathi, R.; Imai, T. Understanding the performance of corona aged epoxy nano micro composites. Micro Nano Lett. 2018, 13, 1280-1285. [CrossRef]

32. Liang, M.; Wong, K. Improving the Long-term Performance of Composite Insulators Use Nanocomposite: A Review. Energy Procedia 2017, 110, 168-173. [CrossRef]

33. Das, S.; Gupta, N. Charge trapping and transport phenomenon in aged and unaged epoxy resin and polyethylene. Int. Trans. Electr. Energy Syst. 2014, 25, 948-957. [CrossRef]

34. Preetha, P.; Thomas, M.J.; Ranjan, R. Electrothermal ageing of epoxy nanocomposites. IEEE Trans. Dielectr. Electr. Insul. 2012, 19, 2081-2089. [CrossRef]

35. Ning, X.; Xiang, Z.; Peng, Z.; Zhang, S.; Chen, S. Effect of UV ageing on space charge characteristics of epoxy resin and its nanocomposites. In Proceedings of the 2013 IEEE International Conference on Solid Dielectrics (ICSD), Bologna, Italy, 30 June-4 July 2013; pp. 784-787.

36. Laghari, J.; Hammoud, A. A Brief Survey of Radiation Effects on Polymer Dielectrics. IEEE Trans. Nucl. Sci. 1990, 37, 1076-1083. [CrossRef]

37. Chen, G.; Zhong, L.; Xie, H.; Banford, H.; Davies, A. The influence of oxidation on space charge formation in gamma-irradiated low-density polyethylene. Radiat. Phys. Chem. 2003, 66, 247-255. [CrossRef]

38. Chen, G.; Banford, H.M.; Davies, A.E. The influence of gamma radiation on space charge formation in low-density polyethylene. In Proceedings of the Conference on Electrical Insulation and Dielectric Phenomena-CEIDP '96, Millbrae, CA, USA, 23 October 1996; pp. 821-824.

39. Nogueira, P.; Torres, A.; Abad, M.J.; Cano, J.; Barral, L. Effect of water sorption on the structure and mechanical properties of an epoxy resin system. J. Appl. Polym. Sci. 2001, 80, 71-80. [CrossRef]

40. Zou, C.; Fothergill, J.C.; Rowe, S.W. The effect of water absorption on the dielectric properties of epoxy nanocomposites. IEEE Trans. Dielectr. Electr. Insul. 2008, 15, 106-117. [CrossRef]

41. Wang, L.; Wang, K.; Chen, L.; He, C.; Zhang, Y. Hydrothermal effects on the thermomechanical properties of high performance epoxy/clay nanocomposites. Polym. Eng. Sci. 2005, 46, 215-221. [CrossRef]

42. Pitarresi, G.; Toscano, A.; Alessi, S. Fracture toughness of synthesised high-performance epoxies subject to accelerated water aging. Polym. Test. 2018, 68, 248-260. [CrossRef]

43. Chen, G.; Hao, M.; Xu, Z.; Vaughan, A.; Cao, J.; Wang, H. Review of high voltage direct current cables. CSEE J. Power Energy Syst. 2015, 1, 9-21. [CrossRef]

44. Montanari, G.; Morshuis, P. Space charge phenomenology in polymeric insulating materials. IEEE Trans. Dielectr. Electr. Insul. 2005, 12, 754-767. [CrossRef]

45. Wang, Y.; Wu, J.; Yin, Y. Research progress on space charge measurement and space charge characteristics of nanodielectrics. IET Nanodielectr. 2018, 1, 114-121. [CrossRef]

46. Zhang, Y.; Christen, T.; Meng, X.; Chen, J.; Rocks, J. Research progress on space charge characteristics in polymeric insulation. J. Adv. Dielectr. 2016, 6, 1630001. [CrossRef]

47. Noah, P.M.; Zavattoni, L.; Agnel, S.; Notingher, P.; Laurentie, J.; Guille, O.; Vinson, P.; Girodet, A. Measurement of space charge distribution in alumina-filled epoxy resin for application in HVDC GIS. In Proceedings of the 2017 IEEE Conference on Electrical Insulation and Dielectric Phenomenon (CEIDP), Fort Worth, TX, USA, 22-25 October 2017; pp. 613-616.

48. Wang, S.; Luo, S.; Tu, Y.; Wang, C.; Qin, S. Effect of polarity reversal on space charge properties of CB/LDPE composite under DC field. IEEE Trans. Dielectr. Electr. Insul. 2017, 24, 1349-1354. [CrossRef] 
49. Chen, X.; Wang, X.; Wu, K.; Peng, Z.R.; Cheng, Y.H.; Tu, D.M. Effect of voltage reversal on space charge and transient field in LDPE films under temperature gradient. IEEE Trans. Dielectr. Electr. Insul. 2012, 19, 140-149. [CrossRef]

50. Chen, G.; Davies, A.; Banford, H. Influence of radiation environments on space charge formation in $\gamma$-irradiated LDPE. IEEE Trans. Dielectr. Electr. Insul. 1999, 6, 882-886. [CrossRef]

51. Montanari, G.; Palmieri, F. The effect of humidity on space charge accumulation in XLPE. In Proceedings of the 2003 Annual Report Conference on Electrical Insulation and Dielectric Phenomena, Albuquerque, NM, USA, 19-22 October 2003; pp. 205-208.

52. Lewis, T.J. Interfaces: Nanometric dielectrics. J. Phys. D Appl. Phys. 2005, 38, 202-212. [CrossRef]

53. Tanaka, T.; Kozako, M.; Fuse, N.; Ohki, Y. Proposal of a multi-core model for polymer nanocomposite dielectrics. IEEE Trans. Dielectr. Electr. Insul. 2005, 12, 669-681. [CrossRef]

54. Ahmed, N.; Srinivas, N. Review of space charge measurements in dielectrics. IEEE Trans. Dielectr. Electr. Insul. 1997, 4, 644-656. [CrossRef]

55. Huner, U. Effect of Water Absorption on the Mechanical Properties of Flax Fiber Reinforced Epoxy Composites. Adv. Sci. Technol. Res. J. 2015, 9, 1-6. [CrossRef]

56. Chen, G.; Chong, Y.L.; Fu, M. Calibration of the pulsed electroacoustic technique in the presence of trapped charge. Meas. Sci. Technol. 2006, 17, 1974-1980. [CrossRef]

57. Dissado, L.; Laurent, C.; Montanari, G.; Morshuis, P. Demonstrating a threshold for trapped space charge accumulation in solid dielectrics under dc field. IEEE Trans. Dielectr. Electr. Insul. 2005, 12, 612-620. [CrossRef]

58. Alijagic-Jonuz, B. Dielectric Properties and Space Charge Dynamics of Polymeric High Voltage DC Insulating Materials. Ph.D. Thesis, Faculty of Electrical Engineering, Mathematics and Computer Science, Delft, The Netherlands, 17 December 2007.

59. Montanari, G.; Fabiani, D. Evaluation of dc insulation performance based on space-charge measurements and accelerated life tests. IEEE Trans. Dielectr. Electr. Insul. 2000, 7, 322-328. [CrossRef]

60. Zhou, T.-C.; Chen, G.; Liao, R.-J.; Xu, Z. Charge trapping and detrapping in polymeric materials: Trapping parameters. J. Appl. Phys. 2011, 110, 043724. [CrossRef]

61. Chen, G.; Fu, M. The Influence of Gamma Irradiation on Space Charge in LDPE. In Proceedings of the 2006 IEEE 8th International Conference on Properties and applications of Dielectric Materials, Bali, Indonesia, 26-30 June 2006; pp. 131-134.

62. Liu, P.; Ning, X.; Peng, Z.; Xiang, Z.; Feng, H.; Zhang, H. Effect of temperature on space charge characteristics in epoxy resin. IEEE Trans. Dielectr. Electr. Insul. 2015, 22, 65-71. [CrossRef]

63. Fabiani, D.; Montanari, G.C.; Testa, L. Effect of aspect ratio and water contamination on the electric properties of nanostructured insulating materials. IEEE Trans. Dielectr. Electr. Insul. 2010, 17, 221-230. [CrossRef]

64. Saha, D.; Anisimov, A.G.; Groves, R.M.; Tsekmes, I.A.; Morshuis, P.H.F.; Kochetov, R. Epoxy-hBN nanocomposites: A study on space charge behavior and effects upon material. IEEE Trans. Dielectr. Electr. Insul. 2017, 24, 1718-1725. [CrossRef]

65. Montanari, G. Relation between space charge and polymeric insulation ageing: Cause and effect. IEE Proc. Sci. Meas. Technol. 2003, 150, 53-57. [CrossRef]

66. Fu, M.; Dissado, L.A.; Chen, G.; Fothergill, J.C. Space charge formation and its modified electric field under applied voltage reversal and temperature gradient in XLPE cable. IEEE Trans. Dielectr. Electr. Insul. 2008, 15, 851-860. [CrossRef] 